\title{
SARS-CoV-2/COVID-19 Pandemisi
}

\section{Özer AKGÜL}

\section{$\ddot{O} \mathbf{z}$}

Aralık 2019'un son günlerinde Çin'in Hubei eyaleti Wuhan kentinde etiyolojisi bilinmeyen pnömoni vakaları görülmeye başlanmıştır. Kısa süre sonra Dünya Sağlık Örgütü (DSÖ) bu vakalardaki etkenin Coronavirus ailesinin yeni bir üyesi olduğunu duyurmuş ve genetik analizler sonucu bu etkenin 2003 yılında salgın yapan SARS (Şiddetli Akut Solunum Sendromu) ile yüksek oranda benzerlik gösterdiği belirlenmiştir. DSÖ tarafından virüsün güncel isimlendirmesi SARS-CoV-2, oluşturduğu hastalık ise COVID-19 olarak kabul edilmiştir. Küresel önlem ve karantina çabalarına rağmen virüsün insidansı artmaya devam etmektedir. Laboratuvar yöntemleri ile 145.000 'in üzerinde kişiyi infekte ettiği ve 5.400'den fazla ölümle ilişkilendirilmesinin belirlenmesi ve 130'dan fazla ülkede görülmesi nedenleri ile SARS-CoV-2, DSÖ tarafindan 11 Mart 2020 tarihinde pandemik olarak değerlendirilmiştir. Bu derlemede SARS-CoV-2/COVID-19 ile ilgili güncel durum özetlenmiştir.

Anahtar Kelimeler: SARS-CoV-2, 2019-nCoV, COVID-19

\section{SARS-CoV-2/COVID-19 Pandemic}

\begin{abstract}
In the last days of December 2019, cases of pneumonia of unknown etiology started to appear in Wuhan, China. World Health Organization (WHO) is announced that the agent in these cases was a new member of the Coronavirus family, and as a result of genetic analysis, it was found that this effect was highly similar to the outbreak SARS (Severe Acute Respiratory Syndrome) in 2002. The current nomenclature of the virus was accepted by WHO as SARS-CoV-2, and the disease it caused was COVID-19. Despite global measures and quarantine efforts, the incidence of the virus continues to increase. SARS-CoV-2 was evaluated as a pandemic by the WHO on March 11, 2020, as it infects more than 145,000 people with laboratory methods and is associated with more than 5,400 deaths. In this review, the current situation on SARS-CoV-2 / COVID-19 is summarized.
\end{abstract}

Keywords: SARS-CoV-2, 2019-nCoV, COVID-19

İstanbul Aydın Üniversitesi, Tıp Fakültesi, Tıbbi Mikrobiyoloji Anabilim Dalı

Yazışma Adresi: Dr. Özer AKGÜL, İAÜ Tıp Fakültesi Tıbbi Mikrobiyoloji AD, Beşyol Mah. İnönü Cad. No:38 Küçükçekmece, İstanbul, Türkiye. Tel: +90 4441428

E-mail: ozerakgul@aydin.edu.tr ORCID ID:0000-0002-3802-3270.

Geliş tarihi: 1 Mart 2020 Kabul tarihi: 17 Mart 2020

Doi num: 10.17932/IAU.TFK.2018.008/2020.301/tfk_v03i1001 


\section{Giriş}

Coronavirus $(\mathrm{CoV})$, Coronavirinae alt familyasina ait zarfll, tek iplikli ve pozitif polarite gösteren RNA virüsüdür. $\mathrm{CoV}$ genomu, muhtemelen bilinen en büyük viral RNA'dır $(1,2)$. Önceden, patojenite derecesine göre düşük ve yüksek olarak gruplanarak insanda hastalık oluşturabilen toplamda altı CoV varlığı bilinmektedir. Bunlardan 229E, HKU1, OC43 ve NL63 düşük patojenik özellik göstermekte ve tipik olarak hafif seyirli solunum yolu hastalıklarına neden olmaktadır $(3,4)$. SARS ve Orta Doğu Solunum Sendromu (MERS) CoV'un dâhil olduğu sıklıkla alt solunum yollarını infekte eden ve ağır pnömoni tablosuna neden olabilen CoV'lar ise yüksek patojenik özellik gösteren grup olarak konumlandırılmıştır (5).

İlk kez Kasım 2003'de Çin'in güney kesiminde görülen ve insanlara misk kedilerinden geçiş yapan SARS-CoV-1, 8 aylık bir sürede 8.096 kişiyi infekte etmiş ve $\% 9.6$ 'lık ölüm oranı ile 774'ünün ölümüne neden olmuştur. Yaklaşık 10 yıl sonra ise ilk kez Suudi Arabistan'da tanımlanan ve insanlara tek hörgüçlü develerden geçiş yapan MERS-CoV tanımlanmışırı. SARS-CoV-1'e göre bulaşıcılı̆̆ daha az ancak ölüm oranı daha yüksek olan (\%34.4) MERS-CoV, 2.494 kişiyi infekte etmiş ve 858 ölüme neden olmuştur $(6-8)$.

Aralık 2019'un sonlarında, yeni bir CoV Çin'in Wuhan şehrinde SARS benzeri bir hastalığın ortaya çıkmasına neden olan patojen olarak tanımlanmış DSÖ tarafindan önce 2019-nCoV güncel olarak ise SARS-CoV-2 olarak adlandırılmıştır. Şanghay Halk Sağlığı Klinik Merkezi'nden tam genomik dizi açıklanmış ve yarasalar SARS-CoV-2 için olası bulaş kaynağı olarak değerlendirilmiştir. Wuhan Deniz Ürünleri Toptan Satış Pazarı ise virüsün bulaşında köken bölge olarak belirtilmiş, kısa süre sonra virüsün insandan-insana bulaştığı kesinlik kazanmıştır. 15 Mart 2020 itibariyle SARS-CoV-2, dünyanın dört bir yanındaki 141 ülkede toplam 152.428 kişiyi infekte etmiş ve 5.720 kișinin ölümüne neden olmuştur $(9-11)$.

Uzun y1llardır süren araştırmalara rağmen, insan CoV'ları için spesifik bir aşı veya tedavi geliştirilememiştir. Bu derlemede, SARS-CoV-2'nin virolojik özellikleri, tanı ve korunma yöntemleri ile COVID-19'un klinik özellikleri özetlenmiştir.

\section{Virolojik ve Genomik Özellikler}

SARS-CoV-2, B-CoV grubu içerisindeki Sarbecovirus alt cinsine aittir. Virüsün içerdiği RNA genomu, 9.860 amino asidi kodlayan 29.891 nükleotid (GenBank no. MN908947) içermektedir (12). Bu nükleotid kabaca S, E, M ve N yapisal proteinlerini kodlayan ve 5'UTR-replikaz (orfla/ b)-Spike (S)-Envelope (E)-Membrane (M)Nucleocapsid (N)-3'UTR şeklinde devam eden bir genomik organizasyona sahiptir. Güncel filogenetik analizler SARS-CoV-2'nin 2013'te Çin Yunnan'da izole edilen BatCoV RaTG13 ile \%96.3'lük benzerlik göstermiş ve bu veri virüsün yarasalardan insana geçiş gösterdiği yönündeki hipotezi güçlendirmiştir $(13,14)$.

\section{Epidemiyolojik Veriler}

İlk araştırmalar, Wuhan Deniz Ürünleri Toptan Satış Pazarında bambu fareleri, rakunlar ve yılanlar gibi pazarda satılan vahşi hayvanların yeni virüsün orijinal kaynağı olacağını ileri sürmüştür (15). Kısa süre sonra izlenebilirlik analizi, insanlardaki SARS-CoV-2'nin Rhinolophus türü yarasalar ile ilişkili olabileceğini göstermiştir. Bununla birlikte, SARS-CoV-1'de görülen için misk kedileri ve MERS-CoV'da görülen tek hörgüçlü develer gibi henüz bilinmeyen bir hayvanın yarasalar ve insanlar arasında ara konakçı olması muhtemel olarak değerlendirilmektedir. Güncel olarak yapılan bir araştırmada ise pangolinler yarasa ve insanlar arasındaki ara konak olarak en çok şüphe duyulan hayvan olarak değerlendirilmiş ancak bu hayvanların tek ara konak olamayabileceği de vurgulanmıştır $(16-18)$.

Epidemiyolojik olarak, SARS-CoV-2 dış ortamda yaklaşık 2 saatlik hayatta kalma süresi ile oldukça bulaşıcıdır (19). Bulaştan sonra görülen inkübasyon süresinin genellikle 4-8 gün olduğu ve en uzun süre olan 14 günlük sürenin ise karantina süresi olarak kabul edilmesi önerilmiştir. Tüm yaş grupları SARS-CoV-2 açısından riskli olmakla birlikte, virüsün oluşturduğu COVID-19'un genellikle ileri yaş ve / veya komorbiditesi olan kişilerde görülme olasılığının daha yüksek olduğu bildirilmektedir 
(20). Virüsün ana bulaş yolu damlacık saçılması ile olmakta bunu damlacıkların temas ettiği yüzeylerden eller ile alınan viral partiküllerin ağız, burun ve göz bölgesine götürülmesinin izlediği bildirilmektedir. Virüsün ana bulaş yolları olan damlacık saçılması ve ellerin mukoza ile temas ettirilmesi dışında SARS-CoV-2'nin fekal-oral yol ile de bulaşabileceği düşünülmüş ancak bu bulaş yolu doğrulanamamıştır (21).

İnfeksiyon hastalıklarının genel bulaşma hızı R0 (reprodüksiyon oranı) değeri ile belirlenmektedir. SARS-CoV-2'nin R0 değeri veriler güncellendikçe değişmekle birlikte ortalama 2.68 olarak belirlenmiştir. DSÖ SARS-CoV-2 pandemisindeki en temel amaçlarından birini de virüsün sahip olduğu bu değeri 1'in altına düşürmek olarak belirlemiştir $(22,23)$.

\section{COVID-19 Temel Klinik Özellikler}

COVID-19, bir betacoronavirüs olan SARS-CoV-2 nedeniyle ortaya çıkmaktadır. Yapısal olarak SARS-CoV, insan anjiyotensin dönüştürücü enzim 2 (ACE 2) proteini ile doğrudan etkileşime giren 14 bağlanma bölgesini içeren tanımlanmış bir bileşime sahiptir. Bu amino asitlerden 8'i SARS-CoV2'de korunmuştur. İnsanlarda, koronavirüslerin SARS-CoV ve MERS-CoV tanımlanana kadar hafif solunum yolu infeksiyonlarına neden olduğu düşünülmüştür. SARS-CoV-2'nin ortaya çıkmasının altında yatan kesin patofizyolojik mekanizmalar henüz bilinmemekle birlikte, SARS-CoV-1 ile gösterdiği virolojik benzerlik ağır pnömoninin başlamasına yol açabilecek inflamatuvar yanıtı açıklamaya yardımcı olabilir $(24,25)$.

SARS-CoV-2 için yapılan kısıtlı çalışmalardaki ortalama kuluçka süresi 5-6 gün olarak belirlenmiştir (0-24 gün). En yaygın semptomlar ise ateş (\%87.9), yorgunluk (\%69.6), kuru öksürük $(\% 67.7)$ ve miyalji (\%34.8) olarak belirlenmiştir. Ancak ateşin ilk başvuru aşamasındaki hastaların sadece \%43.8'inde var olduğu ve bunun COVID-19'un ilk bulgusu olmayabileceği bildirilmiştir. Ancak yine de veriler güncellendikçe değişiklik göstermesi muhtemel olan COVID-19'un kliniğinde ateş, kuru öksürük ve solunum sıkıntısı majör bulgular olarak değerlendirilmektedir $(16,22)$.

\section{Tanı}

Global bir sorun haline gelen SARS-CoV-2/ COVID-19 tanısı için tüm ülkelerde olduğu gibi ülkemizde de Sağlık Bakanlığı tanı algoritması geliştirmiş ve olası vakaları tanımlamıştır. Olası vaka tanımına uyan ve infeksiyondan şüphelenilen hastalar için moleküler temelli olan Polimeraz Zincir Reaksiyonu (PCR) test kitleri geliştirilmiştir. Vaka sayısının artmasına paralel olarak infekte olanların belirlenmesi için daha hızlı ve tarama amaçlı strip testler de geliştirilmiştir. Ülkemizde SARS-CoV-2 tanısının doğrulanması Sağlık Bakanlığı tarafından belirlenen referans laboratuvarlar tarafindan gerçekleştirilmektedir (26).

\section{Korunma Yöntemleri}

DSÖ'nün SARS-CoV-2 için pandemi ilan ettiği tarihten sonra korunma önlemleri güncellenmiştir. Ana korunma yöntemleri el yıkama veya alkol bazlı el antiseptikleri kullanılarak ellerin ovulması, damlacık temasının önlenmesi için riskli mesafenin korunması, hasta kişilerin maske takarak sağlık kurum/kuruluşlarına başvurması, yurt dışına zorunlu olmadıkça çıkılmaması ve yurt dişından dönüşlerde 14 günlük karantina süresine uyulması olarak belirlenmiştir (27).

\section{KAYNAKLAR}

1. Fehr AR, Perlman S. Coronaviruses: An overview of their replication and patho-genesis. Methods Mol Biol 2015; 1282: 1-23.

2. Li G, Fan Y, Lai Y et al. Coronavirus infections and immune responses. J Med Virol 2020; 92: 42432.

3. Cui J, Li F, Shi Z-L. Origin and evolution of pathogenic coronaviruses. Nat Rev Microbiol 2019; 17: 181-192.

4. Su S, Wong G, Shi W et al. Epidemiology, genetic recombination, and patho-genesis of coronaviruses. Trends Microbiol 2016; 24: 490-502.

5. Channappanavar R, Perlman S. Pathogenic human coronavirus infections: causes and consequences of cytokine storm and immunopathology. Semin Immunopathol 2017; 39: 529-539. 
6. Drosten C, Günther S, Preiser $\mathrm{W}$ et al. Identification of a novel coron- avirus in patients with severe acute respiratory syndrome. N Engl J Med 2003; 348: 1967-1976.

7. Ksiazek TG, Erdman D, Goldsmith CS et al. A novel coronavirus associated with severe acute respiratory syndrome. N Engl J Med 2003; 348: 1953-1966.

8. WHO. Middle east respiratory syndrome coronavirus (MERS-CoV). 2020.

9. Chan JF-W, Kok K-H, Zhu Z et al. Genomic characterization of the 2019 novel humanpathogenic coronavirus isolated from a patient with atypical pneumonia after visiting Wuhan. Emerg Microbes Infect 2020; 9: 221-236.

10. Huang C, Wang Y, Li X et al. Clinical features of patients infected with 2019 novel coronavirus in Wuhan, China. Lancet 2020; 395: 497-506.

11. WHO. Novel Coronavirus (COVID-19) Situation. https://experience.arcgis.com/experience /685d0ace521648f8a5beeee 1b9125cd

12. Lu R, Zhao X, Li J et al. Genomic characterisation and epidemiology of 2019 novel coronavirus: implications for virus origins and receptor binding. Lancet 2020; 395: 565-574.

13. Paraskevis D, Kostaki EG, Magiorkinis G et al. Full-genome evolutionary analysis of the novel corona virus $(2019-\mathrm{nCoV})$ rejects the hypothesis of emergence as a result of a recent recombination event. Infect Genet Evol 2020; 79: 104212.

14. Zhou P, Yang X-L, Wang X-G et al. A pneumonia outbreak associated with a new coronavirus of probable bat origin. Nature 2020; 579, 270-273.

15. Li Q, Guan X, Wu P et al. Early transmission dynamics in Wuhan, China, of novel coronavirusinfected pneumonia. N Engl J Med 2020; 382: 989998.

16. Wang $\mathrm{D}, \mathrm{Hu} \mathrm{B}, \mathrm{Hu} \mathrm{C}$ et al. Clinical characteristics of 138 hospitalized patients with 2019 novel coronavirus-infected pneumonia in Wuhan, China. JAMA 2020; E1-E9. doi:10.1001/jama.2020.1585
17. Chen N, Zhou M, Dong X et al. Epidemiological and clinical characteristics of 99 cases of 2019 novel coronavirus pneumonia in Wuhan, China: a descriptive study. Lancet 2020; 395: 507-513.

18. Zhang H, Kang Z, Gong $\mathrm{H}$ et al. The digestive system is a potential route of 2019-nCov infection: A bioinformatics analysis based on single-cell transcriptomes. BioRxiv 2020; 1-19. https://doi. org/10.1101/2020.01.30.927806.

19. Lu C-W, Liu X-F, Jia Z-F. 2019-nCoV transmission through the ocular surface must not be ignored. Lancet 2020; 395: e39.

20. Mahase E. China coronavirus: What do we know so far? BMJ 2020; 368: m308.

21. Wu JT, Leung K, Leung GM. Nowcasting and forecasting the potential domes- tic and international spread of the 2019-nCoV outbreak originating in Wuhan, China: A modelling study. Lancet 2020; 395: 689-697.

22. Guan WJ, Ni ZY, Hu Y et al. Clinical Characteristics of Coronavirus Disease 2019 in China. N Engl J Med 2020; 1-13.

23. Michael DC, Susan MP, Mona RL et al. Severe acute respiratory syndrome. Clin Infect Dis 2004; 38: 1407-1420.

24. World Health Organization, Novel Coronavirus (2019-nCoV) Advice for the Public. 2020.

25. Bespoke, Bebot Launches Free Coronavirus Information Bot. 2020.

26. Türkiye Cumhuriyeti Sağlık Bakanlığı Halk Sağllı̆̆ Genel Müdürlüğü. COVID-19 Algoritmalar. https://hsgm.saglik.gov.tr/tr/covid19-algoritmalar

27. Türkiye Cumhuriyeti Sağlık Bakanlığı Halk Sağllı̆̆1 Genel Müdürlüğü. COVID-19 (SARSCoV2) Enfeksiyonu Rehberi. Bilim Kurulu Çalı̧̧ması. https://hsgm.saglik.gov.tr/depo/covid19/ rehberler/COVID-19_RehberiV5-25Subat2020.pdf 